\title{
Espaço e Economia: Novos Caminhos, Novas Tensões
}

\author{
Leandro Dias de Oliveira
}

\section{(2) OpenEdition \\ 1 Journals}

\section{Edição electrónica}

URL: http://journals.openedition.org/espacoeconomia/93

DOI: 10.4000/espacoeconomia.93

ISSN: 2317-7837

\section{Editora}

Núcleo de Pesquisa Espaço \& Economia

Refêrencia eletrónica

Leandro Dias de Oliveira, «Espaço e Economia: Novos Caminhos, Novas Tensões », Espaço e Economia [Online], 1 | 2012, posto online no dia 19 janeiro 2013, consultado o 03 maio 2019. URL: http://journals.openedition.org/espacoeconomia/93; DOI : 10.4000/espacoeconomia.93

Este documento foi criado de forma automática no dia 3 Maio 2019

(C) NUPEE 


\title{
Espaço e Economia: Novos Caminhos, Novas Tensões
}

\author{
Leandro Dias de Oliveira
}

1 Em conferência proferida na Faculdade de Formação de Professores da UERJ durante o "II Seminário Nacional Espaço \& Economia: Políticas Territoriais, Intervenção do Estado e Práticas Sociais na Reestruturação do Espaço", em outubro de 2011, Paul Claval, professor da Universidade de Paris-Sorbonne, apontou que o alvo da teoria, em particular na ciência geográfica de origem marxista, tem sido esclarecer a dinâmica do capitalismo. Refletindo sobre a obra de David Harvey -- esta era a proposta daquela histórica conferência! -- Claval fez profícuas reflexões a partir da passagem do fordismo ao regime de acumulação flexível, dos novos sistemas de representações e da crítica ao marxismo outrora praticado, confrontado com os novos interesses pelos movimentos sociais e ênfase do pós-modernismo sobre o espaço. Neste diálogo que aproximou possivelmente os dois mais importantes geógrafos em atividade, Paul Claval reconheceu na obra de David Harvey contribuições inestimáveis, como o sublinhamento da exploração atual, os mecanismos capitalistas de evolução da cidade e o exame dos processos econômicos, de ideologias e das representações. Paul Claval -- cuja vasta e erudita obra trata constantemente das imbricações entre espaço e economia -- traçou naquele evento importantes caminhos de análise para todos os interessados neste campo temático.

2 Assim, não haveria autor mais adequado que Paul Claval para assinar o artigo inaugural da Espaço e Economia: Revista Brasileira de Geografia Econômica. Com tradução do Prof. Dr. Guilherme Ribeiro (UFRRJ), o primeiro artigo desta edição de abertura intitula-se "Espaço e Território: As Bifurcações da Ciência Regional", e tem como escopo pensar a evolução dos vínculos analíticos entre espaço e economia -- que não é linear e se mostra cheio de bifurcações -- tanto no campo teórico-interpretativo quanto no que se refere aos exemplos empírico-concretos. Entre a geografia econômica descritiva [denominada no artigo de geografia econômica première manière] e os modelos espaciais de von Thünen, Weber e Christaller; entre a geografia econômica de Carl Ritter, que se interessava pela difusão espacial das espécies vegetais cultivadas e animais domésticos, e o "novo regionalismo", com os recentes dinamismos local-regionais e a formação de núcleos e 
clusters empresariais, distritos industriais, sistemas produtivos locais e ambientes de inovação, Paul Claval oferece ao leitor uma significante apreciação que conjuga o progresso do campo do conhecimento sobre o qual Espaço \& Economia se identifica com o entendimento das mutações territoriais do modelo político-econômico vigente.

É importante salientar a mensagem embutida neste artigo inicial: ainda que o progresso atinja fortemente o espaço, com a revolução técnica dos transportes de massa, a consolidação dos contêineres para envio dos produtos fabricados, a revolução dos transportes rápidos de pessoas (como o avião ou trens de alta velocidade), esta “compressão espaço-tempo" (HARVEY, 2004) -- que transpõe os obstáculos da distância e aproxima economias (CLAVAL, 2003) -- não anula a geografia. Mesmo com as distribuições espaciais modificadas de maneira nevrálgica, "distância" e "proximidade" permanecem como fatores de apreensão analítica, assim como a atenuação da oposição entre espaços industrializados e espaços em vias de desenvolvimento acaba por viabilizar o estudo das transformações oriundas da reestruturação produtiva e da própria deslocalização industrial (WALLERSTEIN, 2003). Não é demasiado lembrar que a deslocalização industrial, que implica na migração das fábricas dos países centrais para os periféricos, exporta o lado sombrio da produção fabril (trabalho disciplinado e hierarquizado, contaminação ambiental) para lugares invisíveis ao mundo desenvolvido (ŽIŽEK, 2009), tornando-se prova cabal de que assuntos de natureza econômica trazem consigo irreversivelmente embutida a questão social.

O segundo artigo desta edição chama-se "As Marcas das Metamorfoses do Capitalismo Contemporâneo e suas Implicações no Espaço Geográfico: o caso do Wal-Mart", de autoria de Pedro Henrique Ferreira Costa, doutorando em geografia pela UNESP - Rio Claro, e de Paulo Roberto Teixeira Godoy, professor assistente-doutor da mesma universidade. Os autores empreendem uma investigação sobre a rede Wal-Mart, apontando-a como exemplo de empresa capitalista do século XXI. Esta rede -- a mais importante rede varejista norte-americana da atualidade -- inicia, a partir da década de 1990, o seu processo de internacionalização, criando diversas filiais na América Latina, América Anglo-Saxônica (Canadá), Ásia e Europa. Com este espraiamento global, segundo Pedro Costa e Paulo Godoy, a rede Wal-Mart acaba por impor lógicas de dominação no território, desenvolvendo funções de vendedora de bens de consumo diários e nutriz de produção significados e modos vivendi, impondo sua "marca" como estilo de vida. É desta maneira que Costa e Godoy asseveram que a rede Wal-Mart, como representante efetiva do capitalismo contemporâneo, "não cria a mercadoria, mas [cria] o mundo onde a mercadoria existe".

5 No campo da Geografia Econômica, é salutar se pensar o caráter multifacetado deste modelo de meta-capitalismo contemporâneo, onde a mutabilidade se torna "marca" e "ideologia", ora transformando-se em toda sua conjuntura, nas novas composições entre indústria, comércio e informação, ora mantendo-se inalterado em sua forma concreta, como na exploração massiva do trabalho tão comumente praticada de forma extemporânea na periferia mundial. Com base em trabalhos de Karl Marx, Max Weber e Fernand Braudel, Paulo Costa e Pedro Godoy demonstram que os alicerces do capitalismo -- a organização e a produção de mercadorias, a extorsão do trabalho, a prestação de serviços remunerados, a propriedade privada, a sociedade em classes, entre tantos outros -- permanecem inalterados, mas foram acoplados desde o pós-guerra às mudanças socioculturais, econômicas e políticas que permitiram um novo modelo de reprodução do mundo e um novo modelo de acumulação. A fábrica -- a mesma que estava condenada à 
supressão pelo advento da Sociedade Pós-Industrial (BELL, 1973), imersa em um profundo processo de reformulação (Ver: MARTIN, 1996) -- deixou de produzir apenas mercadorias para manufaturar subjetividades, através da produção em larga escala de um inextricável apetite pelo consumo, produzindo um incessante imaginário coletivo de efemeridade de cada mercadoria. Com esta espetacularização do real, cada indivíduo carrega consigo uma etiqueta e se torna um out-door gratuito, tornando-se concomitantemente "consumidor" e "propagador", e justapondo "consumo" e "informação". Neste "capitalismo cognitivo" que extrapola o conceito de necessidade, o homem se torna prisioneiro do espaço (SANTOS, 1978), este elo outrora real com o universo que o cerca, mas que se consolida paulatinamente como simulacro do mundo vivido.

6 O terceiro artigo deste primeiro número de Espaço \& Economia: Revista Brasileira de Geografia Econômica chama-se "O Surgimento de Novas Regiões Metropolitanas no Brasil: uma discussão a respeito da criação da Região Metropolitana de Sorocaba (SP)", de Ilson Juliano Barreto, também doutorando em geografia da UNESP, campus Rio Claro. Centrado

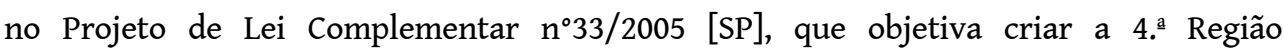
Metropolitana do Estado de São Paulo -- a saber, a Região Metropolitana de Sorocaba -Ilson Barreto perfaz uma crítica aos critérios na constituição de novas regiões metropolitanas no Brasil, por vezes fluídos e demasiado diversificados. A partir de um olhar específico sobre o contingente populacional metropolitano, o autor apresenta de antemão uma discrepância do modelo recente: enquanto a Região Metropolitana de São Paulo, a maior do país, possui trinta e nove municípios integrantes e população próxima a vinte milhões de habitantes, a Região Metropolitana do Sudoeste Maranhense possui apenas oito municípios integrantes e população pouco superior a trezentos mil habitantes.

7 Destarte, Ilson Barreto traz para a ágora um debate tão atual quando fundamental: com o impacto da alteração promovida pela Constituição Federal de 1988, que fez extravasar quantitativamente as antigas nove regiões metropolitanas até então constituídas -- cujas metrópoles eram capitais de estado --, para as atuais trinta e seis regiões metropolitanas, há uma alteração na própria concepção de metrópole vigente. Afinal, se antes se tratava de uma proposta de integração sob os auspícios do Regime Militar, atualmente o poder decisório nesta matéria pertence aos estados da federação -- algo que se aproxima à transição territorial indicada por Milton Santos (2001), quando este aponta que o "Brasil Unificado" cedeu lugar ao "Brasil Globalizado" --, o que vem acarretando disparidades quantitativas e qualitativas no cenário metropolitano brasileiro. Assim, novos tensionamentos teóricos emergem: [1] o que pode ser denominado metrópole no Brasil atual? [2] Quais critérios devem nortear a criação de uma região metropolitana? [3] Para que e para quem são criadas as novas regiões metropolitanas? Não obstante, o autor estimula uma deliberação inadiável: o compartilhamento de decisões entre os municípios metropolitanos em um processo de gestão integrada - um governo metropolitano? destas novas áreas que se consolidam no cenário urbano-econômico brasileiro.

8 A seguir, o professor adjunto do Instituto de Geografia da UERJ - Universidade do Estado do Rio de Janeiro, Miguel Angelo Ribeiro, assina o artigo "Transformações Socioeconomicas e Mudanças na Rede de Localidades Centrais Fluminense: o papel de Campos dos Goytacazes, Macaé e Itaperuna - 1966/2007", cujo escopo foi realizar uma revisão comparativa entre 1966 e 2007, confrontando dados obtidos junto ao IBGE (Instituto Brasileiro de Geografia e Estatística). Não há dúvidas que o intermezzo de quarenta anos permite uma leitura fiável das transformações políticas, sociais e 
econômicas verificadas nos três centros selecionados, calcadas principalmente nas mutações de ordem urbana no que se refere às funções de hierarquia e polarização.

Baseado nos estudos seminais de Walter Christaller, e também dos geógrafos brasileiros Roberto Lobato Corrêa e Milton Santos, Miguel Angelo Ribeiro empreende um tratamento profícuo dos dados do IBGE e busca estabelecer as áreas presentes de atuação dos centros urbanos do Norte Fluminense. Com longa trajetória de estudos sobre a Geografia Fluminense, e, portanto, profundo conhecedor das transformações recentes do estado do Rio de Janeiro, particularmente do interior -- como a modernização parcial da agricultura, aumento da especulação imobiliária e do turismo, a exploração do petróleo na Bacia de Campos e a reestruturação industrial fluminense -- o autor aponta, por exemplo, que Macaé em 1966 apresentava-se na hierarquia urbana fluminense como centro local, sob a influência de Campos dos Goytacazes, mas em 2007 acaba alçado à categoria de Centro Sub-regional vinculando-se diretamente à Metrópole do Rio de Janeiro e apresentando sob seu comando três centros locais: Carapebus, Conceição de Macabu e Rio das Ostras. Já Itaperuna, apesar de localizada na Região de Governo denominada Noroeste Fluminense, apresenta-se centro sub-regional, comanda em 2007 quatro centros de zona: Carangola (MG), Santo Antonio de Pádua, Bom Jesus do Itabapoana e Itaocara, extravasando inclusive os limites estaduais. Todavia, assevera o autor, se há uma diminuição da sua região de influência, Campos dos Goytacazes permanece como pólo de maior hierarquia na Rede Urbana do Norte e Noroeste do estado do Rio de Janeiro, substituindo a centralidade pautada atividade canavieira pelas funções de pólo comercial e de serviços. Trata-se de um estudo que interessa a todos os envolvidos nas interpretações da realidade urbana brasileira, em sua composição e ordem hierárquica.

10 A seguir, no artigo "Geografias do Dissenso: sobre Conflitos, Justiça Ambiental e Cartografia Social no Brasil", Marco Antonio Sampaio Malagodi, professor adjunto do Pólo Universitário de Campos dos Goytacazes da UFF (Universidade Federal Fluminense), apresenta uma discussão essencial na contemporaneidade: os "conflitos ambientais", particularmente aqueles originários em lutas pela sobrevivência de grupos sociais ameaçados por impactos indesejáveis no território. Trata-se, segundo o autor, de uma luta que extrapola a "disputa por recursos", pois envolve questões simbólicas, identitárias e de legitimidade para com o espaço.

11 Inspirado principalmente nas reflexões de Henri Acserald (Ver, p.ex.: ACSERALD, 2004), Marco Malagodi aproxima as mutações da ordem político-econômica e o descrédito do modelo de desenvolvimento capitalista com a emersão e fortalecimentos das lutas múltiplas, como os conflitos de ordem "ambiental". Apresenta, assim, o enfrentamento entre aqueles que discutem sobre a "natureza a ser conservada" (estoque de valor para o mercado) e a "natureza a ser destruída" (campo de expansão de empreendimentos incompatíveis com sua conservação), e relaciona o papel das "tecnologias de consenso", um mecanismo ideológico que desqualifica as reivindicações dos grupos sociais atingidos ambientalmente e estimula "soluções" previamente estabelecidas por interesses particulares - qualquer semelhança com as inúmeras Agendas 21 Locais que se multiplicam cotidianamente pelo globo terrestre não é coincidência! (OLIVEIRA, 2011). Com o olhar voltado para o "Super Porto do Açu", no Norte Fluminense, e para a consolidação do Distrito Industrial de São João da Barra - RJ (do grupo EBX, comandado pelo empresário Eike Batista), que ocasionarão forçosamente desapropriação de agricultores e impactos ambientais de variados matizes, Marco Malagodi estimula que se 
pratique a "arte do desentendimento" como pressuposto da política (RANCIÈRE, 1996), e relembra o ensinamento de Marilena Chauí, para quem "a democracia seria o único regime político onde os conflitos sociais são considerados o próprio princípio de seu funcionamento; impedi-los de se expressar seria destruir a própria democracia". Trata-se, então, de uma exigência para a democratização da produção socioespacial a valorização dos movimentos sociais.

Por fim, no segmento da revista intitulado Trilhas de Pesquisa -- voltado para pesquisas em estágio intermediário de realização --, Leandro Gondim Monteiro, mestrando do curso de Planejamento Urbano e Regional do IPPUR - UFRJ e membro do Núcleo de Pesquisas Espaço e Economia (NUPEE - UERJ) escreve "Do lugar à rede e da rede ao lugar: as estratégias de apropriação do espaço em Itaboraí (RJ) diante das novas lógicas produtivas". Debruçado sobre os impactos da instalação da base da Petrobrás na região do Leste Metropolitano Fluminense, que acaba por reforçar a importância estratégica do território para as aspirações produtivas da empresa, Leandro Monteiro desenvolve pontuações pertinentes: [1] o uso político do anúncio deste mega-empreendimento produtivo; [2] as possibilidades de desenvolvimento econômico do Leste Metropolitano Fluminense; e [3] o desafio de fazer com que um conjunto maior da população local possa usufruir de benefícios oriundos do investimento em tela. Pensando na rearticulação do conceito de desenvolvimento para além do crescimento tecnológico-econômico do capitalismo, Leandro Monteiro propõe que somente a reversão do atual quadro político das cidades do Leste Metropolitano Fluminense -- incluindo uma grave transformação na forma de gestão do território, aproximando poder local e a população -- será capaz de fazer com que a população metropolitana possa usufruir de benesses oriundas destes novos empreendimentos territoriais.

Tratando dos múltiplos caminhos teóricos da relação entre espaço e economia; das metamorfoses cognitivo-ideológicas do capitalismo em sua face contemporânea; da metropolização, em seus aportes político, jurídico e econômico-urbano; da hierarquização urbana, cada vez mais complexificada pelas novas redes multi-escalares; dos novos propósitos e demandas da lutas sociais, como os conflitos de matriz "ambiental"; e por fim, dos impactos econômico-territoriais de mega-empreendimentos como a base da Petrobrás no Leste Metropolitano Fluminense, Espaço e Economia: Revista Brasileira de Geografia Econômica apresenta seu número inaugural com a ambição de estimular reflexões conceituais e possibilidades de interlocução diversas e plurais, almejando se consolidar progressivamente como um canal de interpretação para as múltiplas territorializações socioeconômicas da atualidade.

\section{BIBLIOGRAFIA}

ACSELRAD, Henri (Org). Conflitos Ambientais no Brasil. Rio de Janeiro: Relume/Dumará: Fundação Heinrich Böll, 2004.

BELL, Daniel. 0 Advento da Sociedade Pós-Industrial: Uma Tentativa de Previsão Social. São Paulo: Editora Cultrix, 1973. 
CLAVAL, Paul. La Géographie du XXIe Siècle. Paris: l'Harmattan, 2003.

MARTIN, Ron. Teoria Econômica e Geografia Humana. In: GREGORY, D.; MARTIN, R.; SMITH, G.

(Orgs.). Geografia Humana: Sociedade, Espaço e Ciência Social. Rio de Janeiro: Jorge Zahar Editor, 1996.

OLIVEIRA, Leandro Dias de. A Geopolítica do Desenvolvimento Sustentável: um estudo sobre a Conferência do Rio de Janeiro (Rio-92), 2011. Tese (Doutorado em Geografia) - Instituto de Geociências, UNICAMP, Campinas - SP, 2011.

RANCIÈRE, Jacques. O Desentendimento: política e filosofia. São Paulo: Editora 34, 1996.

SANTOS, Milton. Por uma Geografia Nova: da Crítica da Geografia a uma Geografia Crítica. São Paulo: Ed. HUCITEC, 1978.

. Brasil: Território e Sociedade no Início do Século XXI. Rio de Janeiro: Record, 2001.

WALLERSTEIN, Immanuel. Mundialização ou Era de Transição? Uma Visão de Longo Prazo da Trajetória do Sistema-Mundo. In: CHESNAIS, François.; DUMÉNIL, Gérard, LÉVY, Dominique, WALLERSTEIN, Immanuel. Uma Nova Fase do Capitalismo? São Paulo: Xamã, 2003.

ŽIŽEK, Slavoj. Violência: seis notas à margem. Lisboa: Editora Relógio D'Água, 2009.

\section{AUTOR}

\section{LEANDRO DIAS DE OLIVEIRA}

Doutor em Geografia pela UNICAMP (Universidade Estadual de Campinas). Professor Adjunto de Geografia Econômica do Depto. de Geociências da UFRRJ - Universidade Federal Rural do Rio de Janeiro. E-mail: leandrodias@ufrrj.br 